\title{
Fructo-oligosaccharides and iron bioavailability in anaemic rats: the effects on iron species distribution, ferroportin-1 expression, crypt bifurcation and crypt cell proliferation in the caecum
}

\author{
Alexandre R. Lobo ${ }^{1}$, Eduardo H. S. Gaievski ${ }^{1}$, Eduardo De Carli ${ }^{1}$, Eliana P. Alvares ${ }^{2}$ and Célia Colli ${ }^{1 *}$ \\ ${ }^{1}$ Department of Food and Experimental Nutrition, Faculty of Pharmaceutical Sciences, University of São Paulo, \\ Professor Lineu Prestes Avenue 580, Bloco 14, 05508-900 São Paulo, SP, Brazil \\ ${ }^{2}$ Department of Cell and Developmental Biology, Institute of Biomedical Sciences, University of São Paulo, \\ Professor Lineu Prestes Avenue 1524 (ICB1), 05508-900 São Paulo, SP, Brazil
}

(Submitted 12 February 2014 - Final revision received 19 June 2014 - Accepted 4 July 2014 - First published online 5 September 2014)

\begin{abstract}
The present study investigated the effects of fructo-oligosaccharides (FOS) on the bioavailability of Fe from ferric pyrophosphate (FP), a water-insoluble compound, in Fe-deficient anaemic rats that were subjected to a $\mathrm{Hb}$ repletion assay. Male Wistar rats ( $n$ 64) were fed adequate or low $(8 \mathrm{mg} / \mathrm{kg}$ ) Fe diets for $15 \mathrm{~d}$ followed by 1 or 2 weeks of Fe repletion with diets providing $35 \mathrm{mg}$ Fe/kg as ferrous sulphate (FS), FP or FP that was mixed with $7.5 \%$ FOS in the form of yacon flour or Raftilose P95 (RAF), a purified source of FOS. The effects of FOS were observed within the 1st week of the repletion period. Fe bioavailability was improved by FOS supplementation, as measured by Hb regeneration efficiency and hepatic Fe stores, which were more pronounced in the RAF group. Moreover, RAF supplementation resulted in a higher biological value relative to that of the FP group. FOS supplementation resulted in caecal enlargement, in addition to acidification and Fe species redistribution in the caecal contents relative to the control rats. These effects occurred concomitantly with decreased ferroportin (FPN)-1 expression in the caecal mucosa, which was similar in magnitude to that observed in the FS group. Caecum mucosal morphometry was influenced by FOS supplementation, whereas crypt fission and cell proliferation were highest in the caecum of the RAF group. These results reinforce the effects of FOS as Fe bioavailability enhancers in anaemic rats that are sustained by early changes in their caecal environment (decreased mucosal FPN-1 expression and increased Fe absorbability, crypt fission and cellularity).
\end{abstract}

Key words: Fructo-oligosaccharides: Iron: Bioavailability: Caecum: Rats

The type and amount of dietary fibre that reaches the large intestine and the extent to which it is fermented by intestinal bacteria (i.e. its fermentability) are important factors for understanding its overall effects. In general, the bacterial fermentation of non-digestible carbohydrates affects the following: (1) the luminal environment, by influencing the composition and/or activity of the gut microbiota and the physico-chemical properties of the intestinal content ${ }^{(1,2)}$, and (2) the intestinal epithelium, by regulating the gut hormone response and/or altering the intestinal barrier function, including the stimulation of mucus production and the regulation of cell proliferation, migration and survival, cellular permeability, and the mucosal immune system ${ }^{(3-6)}$. However, other factors could also modulate the fermentative process including the digestibility of food matrix components (such as resistant proteins, lipids and some micronutrients), intestinal motility and inter-individual differences in gut microbiota composition $^{(5,7-9)}$.

In recent years, several studies have also emphasised the effects of inulin-type fructans (ITF), such as fructo-oligosaccharides (FOS) and inulin, on the intestinal absorption of minerals. The acidification of intestinal contents from SCFA production by bacterial ITF fermentation increases mineral solubility and absorbability ${ }^{(10,11)}$. Furthermore, dietary ITF seem to affect mineral absorption in the large intestine by altering the permeability of tight junctions and the gene expression of mineral transporters such as calbindin- $\mathrm{D}_{9 \mathrm{k}}$ (for $\mathrm{Ca}$ ), divalent metal transporter (DMT-1) (for Fe) and zinc transporter 1 (ZnT1) (for Zn), supporting an effect on both paracellular and transcellular absorption ${ }^{(12-14)}$. In addition, changes in the mucosal architecture of the intestine as a result of increases in both the cellularity and number of

Abbreviations: CT, control; FOS, fructo-oligosaccharides; FP, ferric pyrophosphate; FPN, ferroportin; FS, ferrous sulphate; HRE, Hb regeneration efficiency; ID, Fe deficient; ITF, inulin-type fructans; RAF, Raftilose P95; RBV, relative biological value; YF, yacon flour. 
crypts are factors that could contribute to an increase in the absorptive surface for mineral uptake ${ }^{(3,4,7,15)}$. These effects are reflected in the improved bioavailability of minerals, as demonstrated by the increased retention in their target tissues $^{(7,12-18)}$

We have previously demonstrated the positive effects of short-chain ITF (FOS), a rapidly fermentable fibre, on the bioavailability of $\mathrm{Ca}^{(7,15-17)}, \mathrm{Mg}^{(7,15,16)}$ and $\mathrm{Fe}^{(17,18)}$ in rats fed diets containing purified and non-purified ITF sources. In the present study, we used a $\mathrm{Hb}$ depletion-repletion method resembling the one proposed by the $\mathrm{AOAC}^{(19)}$ to investigate the effects of FOS on Fe bioavailability in anaemic rats. The effects of FOS as Fe bioavailability enhancers were confirmed and such effects were sustained by early changes in the caecal environment (decreased mucosal ferroportin (FPN)-1 expression and increased Fe absorbability and crypt bifurcation and cellularity).

\section{Experimental methods}

The experimental protocol was approved by the Commission on Ethics in Animal Experiments of the Faculty of Pharmaceutical Sciences at the University of São Paulo (FCF/USP) (CEEA 213/2009 FCF-USP) according to the guidelines of the Brazilian College on Animal Experimentation.

\section{Iron deficiency protocol}

Female Wistar rats $(n$ 12) were obtained from the colonies for Animal Experimentation at FCF/USP, and each of them was breast-feeding six to eight male pups. These rats were housed in plastic cages with ripcurl and given an Fe-deficient powder diet ${ }^{(19)}$ (8 mg Fe/kg; $n 10$ female rats) or an AIN-93M diet $^{(20)}$ ( $n 2$ female rats) for $21 \mathrm{~d}$.

On weaning day, a total of eighty-eight male rats initially weighing 54-58g were transferred to individual stainlesssteel wire-mesh metabolism cages (to limit coprophagy) under controlled temperature $\left(22 \pm 2^{\circ} \mathrm{C}\right)$ and relative humidity $(55 \pm 10 \%)$ with a $12 \mathrm{~h}$ dark $-12 \mathrm{~h}$ light cycle (lights on from 08.00 to 20.00 hours). Rats were given access to demineralised water ad libitum and an Fe-deficient powder diet (ID group; $n$ 80) or an AIN-93G diet $^{(20)}$ (control (CT) group; $n$ 8) for $14 \mathrm{~d}$ (depletion period). During this period, ten ID rats were selected to determine their body weight and Hb concentration values. When the $\mathrm{Hb}$ concentration of these rats reached a mean value of $60 \mathrm{~g} / \mathrm{l}$, it was determined in all rats.

\section{Hb repletion assay}

For the $\mathrm{Hb}$ repletion assay, sixty-four rats were selected from the Fe-deficient group ( $n$ 80). These rats were distributed into four groups based on the product of body weight $(\mathrm{g})$ and $\mathrm{Hb}$ concentration $(\mathrm{g} / \mathrm{l})$. Rats were fed modified AIN-93G diets containing $35 \mathrm{mg} \mathrm{Fe} / \mathrm{kg}$ as microencapsulated ferrous sulphate $(\mathrm{FS})^{(21)}$ with alginate (Fermavi Eletroquímica Ltda) (FS group; $n$ 16) or ferric pyrophosphate (FP; Fermavi Eletroquímica Ltda) in a mineral mix. FP was added to the diets of three different groups: one diet without fructan supplementation (FP group; $n$ 16) and two other diets with fructan supplementation, with yacon (Smallanthus sonchifolius (Poepp \& Endl.) H. Robinson, Asteraceae) flour (YF group; $n$ 16) or Raftilose P95 (Clariant S/A) (RAF group; $n$ 16) at $7.5 \%$ FOS $(75 \mathrm{~g} / \mathrm{kg}$ diet) (repletion period; Table 1$)$. Rats were killed after 1 (week $1 ; n 8$ per group) and 2 (week $2 ; n 8$ per group) weeks of repletion. The remaining eight healthy rats (CT group) continued to be fed the AIN-93G diet during the repletion period, and at the end of this period (week 2), the mean $\mathrm{Hb}$ concentration of this group was 140 (SD 22) g/l.

Rats were anaesthetised through the intraperitoneal route with a $1: 2(\mathrm{v} / \mathrm{v})$ mixture of ketamine $(10 \mathrm{mg} / \mathrm{kg}$ body weight; Vetaset; Fort Dodge Animal Health) and xylazine ( $25 \mathrm{mg} / \mathrm{kg}$ body weight; Virbaxil $2 \%$, Virbac). After anaesthesia, blood was collected from each rat and the liver was perfused through the subhepatic vein with a $\mathrm{NaCl}$ solution ( $9 \mathrm{~g} / \mathrm{l})$ to drain blood out of the organ. The liver was then removed, rinsed with saline, weighed and stored at $-20^{\circ} \mathrm{C}$ until analysis. The caecum was cut adjacent to the ileocaecal valve and the caecocolonic junction, weighed (whole caecum) and placed in a Petri dish with ice ${ }^{(22)}$. The $\mathrm{pH}$ of caecal content was measured in situ by inserting an electrode (UP-25; Denver Instrument, Denver) through the ileocaecal junction. The caecum was then cut open along the small curvature and aliquots of the caecal contents were collected, frozen in liquid $\mathrm{N}_{2}$ and adequately stored at $-20^{\circ} \mathrm{C}$ for $\mathrm{Fe}$ fractionation analysis. The caecal wall was flushed clean in ice-cold saline, blotted dry and weighed (to determine the caecal wall weight). The weight of the caecal contents was calculated by taking the difference between the weights of the whole caecum and those of the caecal wall. The caecal mucosa was scraped off with a glass slide before being snap-frozen in liquid $\mathrm{N}_{2}$ and stored at $-80^{\circ} \mathrm{C}$ until analysis. In addition, tissue samples from the caecal wall were fixed in formaldehyde solution and stored in $70 \%$ ethanol.

Table 1. Formulation of the experimental diets

\begin{tabular}{|c|c|c|c|c|}
\hline Ingredients (\%) & FS & FP & RAF & YF \\
\hline Casein* & $20 \cdot 9$ & 20.9 & $20 \cdot 9$ & 20.9 \\
\hline Fibre & $5 \cdot 0$ & $5 \cdot 0$ & $5 \cdot 0$ & 5.0 \\
\hline Soyabean oilt & $7 \cdot 0$ & $7 \cdot 0$ & $7 \cdot 0$ & $7 \cdot 0$ \\
\hline L-Cystine & 0.3 & 0.3 & 0.3 & 0.3 \\
\hline Choline bitartrate $(41.1 \%$ choline) & 0.25 & 0.25 & 0.25 & 0.25 \\
\hline Vitamin mixtureł & $1 \cdot 0$ & 1.0 & 1.0 & 1.0 \\
\hline Mineral mixture§ & 3.5 & 3.5 & 3.5 & 3.5 \\
\hline Sucrose & $10 \cdot 0$ & $10 \cdot 0$ & $2 \cdot 5$ & - \\
\hline Maize starch & 52.05 & $52 \cdot 05$ & 51.45 & $46 \cdot 35$ \\
\hline Raftilose P95\| & - & - & $8 \cdot 1$ & - \\
\hline Yacon flour & - & - & - & $15 \cdot 7$ \\
\hline
\end{tabular}

FS, ferrous sulphate; FP, ferric pyrophosphate; RAF, Raftilose P95; YF, yacon flour.

${ }^{*}$ Casein $=85 \%$ protein $(\mathrm{N} \times 6.25)$.

† Cargill Agrícola S/A.

$\ddagger$ AIN-93-VX vitamin mixture ${ }^{(20)}$

$\S$ Modified from a mineral mixture (AIN-93G-MX $\left.{ }^{(20)}\right)$ : $\mathrm{Fe}_{4}\left(\mathrm{P}_{2} \mathrm{O}_{7}\right)_{3}$ at $4.12 \mathrm{~g} \mathrm{Fe} / \mathrm{kg}$ or $\mathrm{FeSO}_{4} \cdot \mathrm{H}_{2} \mathrm{O}$ at $2.71 \mathrm{~g} \mathrm{Fe} / \mathrm{kg}$ mix was utilised in the mineral mix of the experimental diets.

\| Orafti Active Food International (Clariant), 93\% inulin-type fructans (ITF)

ๆ São Sebastião Farm (Ibiúna); $48 \%$ ITF, 49\% fructose, $11 \%$ total dietary fibre and $4 \mu \mathrm{g} \mathrm{Fe} / \mathrm{g}$. 


\section{Chemical composition of yacon flour and experimental diets}

The diet fed to the CT group was formulated according to the AIN-93G diet ${ }^{(20)}$. In the RAF and YF diets (Table 1), maize starch, sucrose and dietary fibre were quantitatively substituted, taking into consideration the carbohydrate content of the FOS sources. The Raftilose P95 used in the present study was donated by Clariant S/A. According to the analysis certificate, this product contains approximately 93\% ITF-containing molecules (GFn) with an average polymerisation degree of 4 (FOS). The FOS in RAF were obtained by the partial hydrolysis of inulin, which was extracted from chicory roots (Cichorium intybus). Yacon tuberous roots were harvested 8 months after cultivation, and they were obtained from the Company of General Warehouses of São Paulo and processed properly as described in previous studies ${ }^{(15,18)}$. The roots were autoclaved $\left(121^{\circ} \mathrm{C}, 20 \mathrm{~min}\right.$ ), freeze-dried (Liotécnica Indústria e Comércio Ltda) and ground to obtain flour.

The total fructans and fructose in YF were analysed according to the method of Steegmans et al. ${ }^{(23)}$ using an enzymatic, spectrophotometric kit (R-Biopharm AG) for glucose and fructose determination with hexokinase, glucose-6-phosphate dehydrogenase and phosphoglucose isomerase. The total dietary fibre was determined by enzymatic-gravimetric $\operatorname{method}^{(24)}$. Fe concentrations in the diets and in the YF were determined by atomic absorption spectrophotometry (AAnalyst 100; Perkin Elmer) using a hollow cathode lamp at $283.4 \mathrm{~nm}$ and a $0.2 \mathrm{~nm}$ slit after wet digestion $\left(\mathrm{HNO}_{3}-\right.$ $\left.\mathrm{H}_{2} \mathrm{O}_{2}, 5: 1 ; \mathrm{v} / \mathrm{v}\right)$. The working standard solution was prepared with $\mathrm{FeCl}_{3}$ (Tritisol; Merck). Yacon flour analysis identified $48 \%$ total fructans, $49 \%$ fructose, $11 \%$ total dietary fibre and $4 \mu \mathrm{g} \mathrm{Fe} / \mathrm{g}$. A certified reference material (lyophilised bovine liver, SRM1577c, National Institute of Standards and Technology) was used to check Fe recovery $(\mathrm{Fe}$ value $=$ mean 188 (sD 14) $\mu \mathrm{g} / \mathrm{g}, n$ 6) (certified value, 197 (SD 6) $\mu \mathrm{g} / \mathrm{g}$ ).

\section{Iron bioavailability, hepatic iron concentration and iron fractionation analyses in the caecal contents}

To determine $\mathrm{Hb}$ concentration during the depletion period, blood was obtained by tail puncture. At the time of killing during the repletion period, blood was obtained from the abdominal aorta. Blood $\mathrm{Hb}$ concentration was determined with a commercial kit (reference no. 43, Labtest Diagnóstica) using the cyanide $\mathrm{Hb}$ method $^{(25)}$ and a commercially available control material (Labtest Diagnóstica). The $\mathrm{Hb}$ Fe pool was calculated according to the following equation, assuming that $6.7 \%$ of the body weight is blood and that $\mathrm{Hb}$ contains $0.335 \% \mathrm{Fe}^{(26)}$ :

Hb Fe pool $(\mathrm{mg})=\frac{(\text { body weight }(\mathrm{g}) \times \mathrm{Hb}(\mathrm{g} / \mathrm{l}) \times 6 \cdot 7 \times 0 \cdot 335)}{10000}$

Values obtained in the $\mathrm{Hb} \mathrm{Fe}$ pool and $\mathrm{Fe}$ intake calculations were used to estimate the $\mathrm{Hb}$ regeneration efficiency
(HRE), according to the following equation ${ }^{(26)}$ :

$$
\operatorname{HRE}(\%)=\frac{(\mathrm{Hb} \text { Fe pool }(\text { final })-\mathrm{Hb} \text { Fe pool }(\text { initial }) \times 100)}{\text { Fe intake }(\mathrm{mg})} \text {. }
$$

The bioavailability of Fe from FS (FS group) was considered as the reference and was therefore assigned a value of $100 \%{ }^{(18,27)}$. Thus, the relative Fe bioavailability, or biological value (RBV) of each FP group (FP, RAF and YF groups), was determined at weeks 1 and 2 of the repletion period as follows:

$$
\operatorname{RBV}(\%)=100 \times \frac{\text { HRE test group }}{\text { HRE FS group }} .
$$

The total Fe in the left lateral lobe of the liver and the caecal contents was determined as described previously for dietary Fe analysis. Caecal contents were subjected to a sequential solubilisation to analyse the intestinal Fe species distribution, as described by Simpson et al. ${ }^{(28)}$, which was modified from Tessier's method ${ }^{(29)}$. In brief, approximately $1 \mathrm{~g}$ of the sample was subjected to extraction under stirring followed by centrifugation $(10000 \boldsymbol{g}$ for $30 \mathrm{~min}$ ). The supernatant was collected and combined with the washed pellet that was obtained by mixing the demineralised water after sample re-centrifugation. Each fraction of the extraction process corresponded to the supernatant added to its wash. The resulting pellet was subjected to the next extraction step. Fe concentrations were determined in the following five fractions: exchangeable (soluble in $1 \mathrm{~m}$-magnesium chloride; for $1 \mathrm{~h}$ at room temperature); carbonate-bound (acid soluble; $1 \mathrm{~m}$-sodium acetate, $\mathrm{pH} 5 \cdot 0$-adjusted with acetic acid, for $4 \mathrm{~h}$ at room temperature); oxide-bound (soluble in 0.04 M-hydroxylamine in acetic acid; for $16 \mathrm{~h}$ at $\left.95^{\circ} \mathrm{C}\right)$; organic matter (soluble after treating with $0.02 \mathrm{M}$-nitric acid and $\mathrm{H}_{2} \mathrm{O}_{2}(\mathrm{pH}$ $5 \cdot 0$-adjusted with nitric acid); for a total of $5 \mathrm{~h}$ at $85^{\circ} \mathrm{C}$ ); residual (the remaining pellet) ${ }^{(28,29)}$. Fe concentrations were obtained directly from calibration curves that were prepared from the solution components used in different extraction steps. The analytical precision for each extraction step was evaluated by subjecting ten subsamples of a caecal content pool to the sequential procedure described above. The pool was obtained by homogenising the caecal contents of male Wistar rats ( $n$ 10; body weight approximately $200 \mathrm{~g}$ ) fed commercial chow (664 mg Fe/kg). CV of $10.5 \%$ (for the organic matter fraction) or lower $(6 \cdot 8,9 \cdot 4,6.3$ and $9.7 \%$ for exchangeable, carbonate-bound, oxide-bound and residual fractions, respectively) were obtained. A comparison of the sum of Fe concentrations in each fraction was consistent with the total Fe concentrations $\left(r^{2} 0.98\right.$; Fe value $=$ mean 13.76 (SD 1.13) v. 13.95 (SD 1.14$) \mu \mathrm{mol} / \mathrm{g}$, respectively).

\section{Immunoblotting}

$\mathrm{N}$-frozen samples of caecal mucosa were homogenised (T10 basic Ultra Turrax; IKA Works, Inc.) in T-PER Tissue Protein Extraction Reagent (Pierce Technology) containing 
protease and phosphatase inhibitors (Pierce Technology). The homogenates were centrifuged at $10000 \mathrm{~g}$ for $5 \mathrm{~min}$, and total protein concentrations in the supernatants were determined using the bicinchoninic acid assay (Pierce Technology). Equal amounts of total protein $(50 \mu \mathrm{g})$ were denatured by boiling for $5 \mathrm{~min}$ in $4 \times$ SDS Laemmli buffer (200 mm-Tris$\mathrm{HCl} \mathrm{pH} \mathrm{6.8,} \mathrm{8 \%} \mathrm{(v/v)} \mathrm{SDS,} \mathrm{40 \%} \mathrm{(v/v)} \mathrm{glycerol,} \mathrm{20 \%} \mathrm{(v/v)}$ $\beta$-mercaptoethanol and $0.4 \%(\mathrm{v} / \mathrm{v})$ bromophenol blue), separated by $12.5 \%$ SDS-PAGE (Fisher Scientific) and then transferred onto nitrocellulose membranes (Whatman). The blots were pre-incubated in Blocker Casein Buffer (Pierce Techno$\operatorname{logy}$ ) for $2 \mathrm{~h}$ at room temperature and then incubated with 1:500 (v/v) diluted rabbit polyclonal anti-FPN1 (Abcam Antibodies) for $14 \mathrm{~h}$ at $4^{\circ} \mathrm{C}$. After being washed three times with 0.1\% PBS-Tween, the blots were incubated with 1:50000 $(\mathrm{v} / \mathrm{v})$ diluted peroxidase-labelled anti-rabbit secondary antibodies (Sigma Chemical Company), and the immunoreactive band signals were visualised with an enhanced chemiluminescence kit (GE Healthcare). ImageQuant 400 equipment (GE Healthcare) and Quantity One Basic software (BioRad Laboratories) were used for scanning the photo-images and for densitometry analysis, respectively. Each membrane was re-probed with 1:50000 (v/v) diluted peroxidase-labelled anti- $\beta$-actin monoclonal antibody (Sigma Chemical Company). FPN protein expression data were normalised to corresponding $\beta$-actin values and expressed as arbitrary units.

\section{Caecal histology}

To perform a histological examination, the fixed tissue fragments were embedded in paraffin and approximately $5 \mu \mathrm{m}$ thick sections were obtained and stained with haematoxylin and eosin. In each crypt, the cells in the left-hand column were counted (cells/hemicrypt) from the bottom to the top of the caecal crypt under an optical microscope. At least thirty hemicrypts per rat were assessed, and only crypts that were cut lengthwise were considered. To determine the percentage of bifurcating crypts, the crypts with an indentation at the base or those presenting longitudinal fission (one crypt mouth and two bases) were considered ${ }^{(30)}$. The calculation was performed by determining the percentage of bifurcating crypts (only crypts cut lengthwise) per microscopic field. To estimate the total number of crypts per microscopic field, the obliquely sectioned crypts were also considered. At least twenty microscopic fields per rat were analysed. To evaluate the metaphase index, each rat was administered a single intraperitoneal injection of vincristine sulphate (Tecnocris, Zodiac Produtos Farmaceuticos S/A; $1 \mathrm{mg} / \mathrm{kg}$ body weight) $2 \mathrm{~h}$ before being killed. The metaphase index was determined by counting the number of cells arrested at metaphase under a light microscope (Nikon). Approximately 2000 cells per rat were counted in longitudinally sectioned crypts using an ocular grid (Zeiss Integration Eyepiece I Kpl 8; Carl Zeiss) at $100 \times$ magnification. The metaphase index was determined as the ratio of the number of arrested metaphases:the total number of cells.

\section{Statistical analysis}

Statistical analysis was performed using Prism 5 for Windows (version 5.00, 2007; Graphpad Software, Inc.). All tests were performed by assuming the bilateral hypotheses and a $5 \%$ significance level. Descriptive statistics were initially used to evaluate the means and standard deviations of the studied variable. During the depletion period, the mean values of the CT and ID groups were compared using an unpaired $t$ test. During the repletion period, the variable means of the groups were compared using an ANOVA. Tukey's post hoc test was used to identify where significant differences occurred. A non-parametric Kolmogorov-Smirnov test was used to verify the normality of the observations, and when the normality hypothesis was rejected, ANOVA was substituted with non-parametric Kruskal-Wallis and Dunn's post hoc tests. The observed power was $85-95 \%$ for most tests.

\section{Results}

Total food and iron intake, body weight gain, iron bioavailability parameters and hepatic iron concentrations

At the end of the depletion period, the blood $\mathrm{Hb}$ concentrations and body weights of the ID group were significantly reduced in comparison with those of the CT group (59 (SD 6) v. 122 (SD 19) g/l, $P<0.0001$, and 82 (SD 18) v. 104 (SD 5) g, $P=0 \cdot 005$, respectively)

During the repletion period, no significant differences were observed in the total food intake among the groups (112 and $260 \mathrm{~g}$ at weeks 1 and 2, respectively, in the FS group). Moreover, there were no differences in total Fe intake (5.5 and $13 \mathrm{mg}$ at weeks 1 and 2, respectively, in the FS group), considering that the different diets had similar Fe concentrations, as measured by atomic absorption spectrophotometry (49.4, $44.9,45.3$ and $47.0 \mathrm{mg} \mathrm{Fe} / \mathrm{kg}$ diet in the FS, FP, RAF and YF diets, respectively). There were no differences in body weights among the groups at the end of week 1, but at week 2, YF supplementation resulted in a higher weight gain in comparison with that in the other groups $(P<0.05)$.

Blood $\mathrm{Hb}$ concentrations, $\mathrm{Hb}$ Fe pool, HRE values, RBV and hepatic $\mathrm{Fe}$ concentrations during the repletion period are shown in Fig. 1. In general, the effects of FOS in anaemic rats were observed within the 1 st week of the repletion period. Hence, considering that blood $\mathrm{Hb}$ concentrations were similar among the groups at the start of this period $(P=0 \cdot 78)$, changes in $\mathrm{Hb}$ concentrations in FOS-fed rats at week 1 were greater than those in the FP group $(P<0.01)$ and similar to those in the FS group. At week 2, there were no differences in blood $\mathrm{Hb}$ concentrations among the groups (Fig. 1(A)). Moreover, no changes were observed in the $\mathrm{Hb}$ Fe pool among the groups throughout the repletion period (Fig. 1(B)).

The efficiency of $\mathrm{Hb}$ recovery reflects the ratio of dietary $\mathrm{Fe}$ conversion into $\mathrm{Hb}$ :the amount of ingested Fe over the course of the repletion period. In the present study, only the RAF group exhibited higher HRE values than the FP group and had HRE values similar to those of the FS group at week 1 of the repletion period $(P<0.05 ;$ Fig. $1(\mathrm{C}))$. The $\mathrm{Hb}$ 

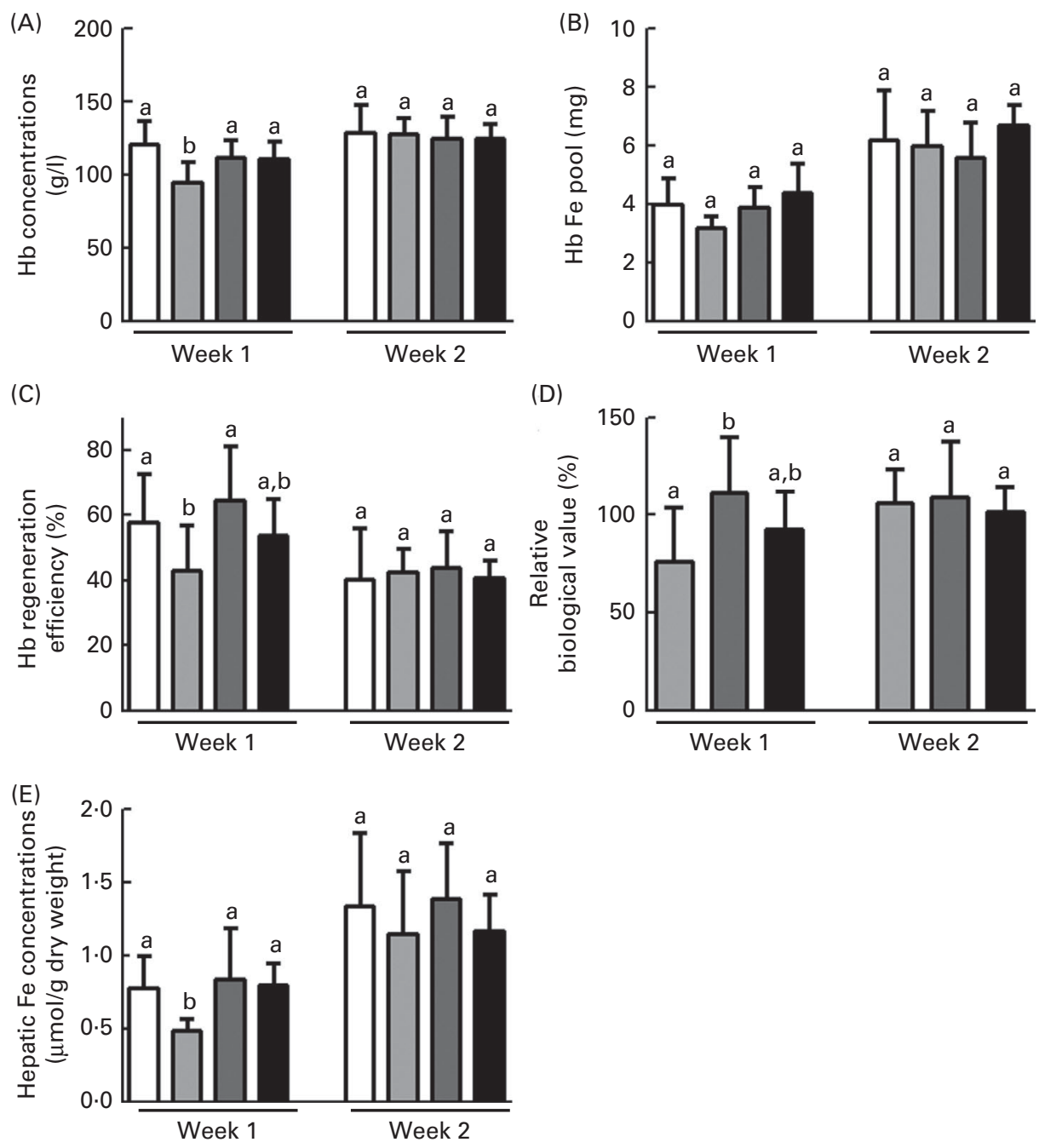

Fig. 1. Effects of fructo-oligosaccharides on the bioavailability of iron from ferric pyrophosphate (FP) during the 1st week of recovery of Hb in iron-deficient rats. The iron bioavailability of iron-deficient rats fed diets containing ferrous sulphate ( $\square$ ), FP ( $\square$ ) or FP supplemented with $7.5 \%$ inulin-type fructans in the form of Raftilose P95 ( $\square$ ) or yacon flour ( $\square$ ) for 1 and 2 weeks (weeks 1 and 2, respectively). (A) Blood Hb concentrations; (B) Hb iron pool; (C) Hb regeneration efficiency; (D) relative biological value; and (E) hepatic iron concentrations. Values are means $(n 8)$, with standard deviations represented by vertical bars. ${ }^{\mathrm{a}, \mathrm{b}}$ Mean values with unlike letters were significantly different $(P<0.05$; ANOVA and Tukey's post hoc tests).

concentration observed at the end of each week during the repletion period (weeks 1 and 2) in the FS group was considered as the reference. Hence, the FS group was used as a reference to express the bioavailability of Fe from FP (FS is assigned a $100 \%$ value) (RBV). The RBV of the FP in the RAF group were higher than those of the FP in the FS group (111\% after the 1st week and 109\% after the 2nd week). These values were significantly higher than those in the FP group at week $1(P<0 \cdot 05$; Fig. 1(D)). Moreover, there was no significant difference in the RBV between rats provided with either dietary FOS source at week 1.

As expected, hepatic Fe concentrations were lower in the FP group than in the FS group at week 1 of the repletion period, whereas FOS supplementation led to the recovery of hepatic Fe stores to levels comparable to those observed in the FS group $(P=0.01$; Fig. $1(\mathrm{E}))$. In addition, there were no differences in hepatic Fe concentrations between the two FOS groups.
Effects of fructo-oligosaccharides on caecal parameters during recovery from anaemia: early changes in iron species distribution, mucosal ferroportin-1 expression, morphometry and crypt cell proliferation

Because the effects of FOS on Fe bioavailability had already been observed at week 1 of the repletion period, the intestinal changes in response to the supplementation of these fermentable fibres were evaluated. The effects of FOS supplementation on caecal parameters (caecum weight, caecal content $\mathrm{pH}$ values and Fe species distribution in the caecal contents) are summarised in Table 2. FOS supplementation resulted in heavier caeca (total, wall and contents), irrespective of the dietary FOS source supplemented, when compared with those of the FP group $(P<0 \cdot 05)$. Moreover, the caecal content $\mathrm{pH}$ was decreased by FOS supplementation, but only the values of the RAF group were significantly different from those of the CT rats $(P<0 \cdot 05)$. Accordingly, although the 
Table 2. Caecal parameters (organ weight, $\mathrm{pH}$ values, total iron concentrations and iron species distribution in the caecal contents) of iron-deficient rats fed diets containing ferrous sulphate (FS) or ferric pyrophosphate (FP) supplemented with $7.5 \%$ inulin-type fructans in the form of Raftilose P95 (RAF) or yacon flour (YF) during the 1st week of recovery of $\mathrm{Hb}$

(Mean values with their standard deviations, $n$ 8)

\begin{tabular}{|c|c|c|c|c|c|c|c|c|c|}
\hline \multirow[b]{3}{*}{ Analyses } & \multicolumn{8}{|c|}{ Dietary treatments } & \multirow[b]{3}{*}{$P$} \\
\hline & \multicolumn{2}{|c|}{ FS } & \multicolumn{2}{|c|}{ FP } & \multicolumn{2}{|c|}{ RAF } & \multicolumn{2}{|c|}{ YF } & \\
\hline & Mean & SD & Mean & SD & Mean & SD & Mean & SD & \\
\hline Caecum wet weight $(g)^{*}$ & $2 \cdot 5^{\mathrm{a}, \mathrm{b}}$ & $1 \cdot 0$ & $1.9^{\mathrm{a}}$ & 0.2 & $6 \cdot 3^{b}$ & $2 \cdot 9$ & $4 \cdot 6^{\mathrm{a}, \mathrm{b}}$ & $2 \cdot 1$ & 0.02 \\
\hline Caecum wet weight $(\mathrm{g} / 100 \mathrm{~g})^{\star}$ & $2 \cdot 0^{\mathrm{a}}$ & 0.6 & $1 \cdot 2^{\mathrm{b}}$ & 0.1 & $3 \cdot 8^{\mathrm{C}}$ & 1.6 & $2 \cdot 6^{\mathrm{c}}$ & $1 \cdot 1$ & 0.03 \\
\hline Caecal wall weight $(\mathrm{g})^{*}$ & $0.39^{\mathrm{a}, \mathrm{b}}$ & 0.08 & $0.37^{a}$ & 0.05 & $0.84^{b}$ & 0.16 & $0.62^{\mathrm{a}, \mathrm{b}}$ & 0.18 & 0.01 \\
\hline Caecal wall weight $(\mathrm{g} / 100 \mathrm{~g})^{*}$ & $0.32^{a, b}$ & 0.02 & $0.23^{\mathrm{a}}$ & 0.03 & $0.52^{\mathrm{b}}$ & 0.07 & $0.37^{a, b}$ & 0.12 & 0.007 \\
\hline \multicolumn{10}{|l|}{ Caecal contents* } \\
\hline Weight $(\mathrm{g})$ & $2 \cdot 1^{\mathrm{a}, \mathrm{b}}$ & 0.9 & $1.5^{\mathrm{a}}$ & 0.2 & $5 \cdot 4^{\mathrm{b}}$ & $2 \cdot 8$ & $3.9^{\mathrm{a}, \mathrm{b}}$ & 1.9 & 0.02 \\
\hline Weight $(\mathrm{g} / 100 \mathrm{~g})$ & $1 \cdot 7^{\mathrm{a}, \mathrm{b}}$ & 0.6 & $0.9^{\mathrm{a}}$ & 0.1 & $3 \cdot 3^{\mathrm{b}}$ & 1.5 & $2 \cdot 3^{\mathrm{a}, \mathrm{b}}$ & $1 \cdot 1$ & 0.02 \\
\hline $\mathrm{pH}$ values & $7 \cdot 1^{\mathrm{a}}$ & 0.1 & $7 \cdot 1^{\mathrm{a}}$ & 0.1 & $6 \cdot 9^{\mathrm{b}}$ & 0.1 & $7 \cdot 0^{\mathrm{a}, \mathrm{b}}$ & 0.2 & 0.02 \\
\hline Total Fe $(\mu \mathrm{mol} / \mathrm{g})$ & $2 \cdot 9^{\mathrm{a}}$ & 0.2 & $2 \cdot 7^{\mathrm{a}}$ & 0.2 & $2 \cdot 8^{\mathrm{a}}$ & 0.1 & $2 \cdot 6^{\mathrm{a}}$ & 0.2 & NS \\
\hline \multicolumn{10}{|l|}{ Fe species distribution $(\mu \mathrm{mol} / \mathrm{g}) \dagger$} \\
\hline Exchangeable & $0.08^{a}$ & 0.02 & $0.07^{\mathrm{a}}$ & 0.01 & $0 \cdot 15^{\mathrm{b}}$ & 0.01 & $0.09^{a}$ & 0.03 & 0.0002 \\
\hline Carbonate-bound & $0.58^{\mathrm{a}}$ & 0.03 & $0.60^{\mathrm{a}}$ & 0.04 & $0 \cdot 12^{\mathrm{b}}$ & 0.05 & $0.11^{\mathrm{b}}$ & 0.04 & $<0.0001$ \\
\hline Oxide-bound & $0 \cdot 20^{\mathrm{a}}$ & 0.05 & $0.20^{\mathrm{a}}$ & 0.04 & $0.50^{\mathrm{b}}$ & 0.11 & $0.29^{a}$ & 0.09 & 0.0003 \\
\hline Organic & \multicolumn{2}{|c|}{ ND } & \multicolumn{2}{|c|}{ ND } & \multicolumn{2}{|c|}{ ND } & \multicolumn{2}{|c|}{ ND } & \\
\hline Residual & $2 \cdot 17$ & 0.40 & 1.86 & 0.23 & 2.07 & 0.16 & $2 \cdot 11$ & 0.26 & NS \\
\hline
\end{tabular}

ND, not detected.

a,b,c Mean values within a row with unlike superscript letters were significantly different $(P<0.05)$

* Data were analysed using ANOVA and Tukey's post hoc tests.

†Data were analysed using non-parametric Kruskal-Wallis and Dunn's post hoc tests.

total Fe concentrations in the caecal contents were not significantly different among the groups, RAF supplementation redistributed $\mathrm{Fe}$ from the carbonate-bound fraction (which is sensitive to $\mathrm{pH}$ changes) to the exchangeable (more bioavailable) and oxide-bound (susceptible to reduction) fractions (Fig. 2). Thus, the concentrations identified for exchangeable Fe were higher in rats fed the RAF diet $(P=0.01)$ than in those fed the YF and CT diets (an increase from 2 to $5 \%$ relative to the total $\mathrm{Fe}$ concentrations in the CT and RAF rats, respectively (Fig. 2)). Similarly, the levels of $\mathrm{Fe}$ bound to oxides were significantly increased by RAF supplementation $(P<0 \cdot 01)$. Fe concentrations in the oxide-bound fraction represented $6-7 \%$ of those in the CT rats and increased to $17 \%$ in RAF rats (Fig. 2). The levels of Fe bound to organic matter were lower than their detection limits, representing a negligible fraction of the total amount of $\mathrm{Fe}$ in the caecal contents (which are therefore not shown in Fig. 2). Fe concentrations in the residual fraction were higher than those observed in any of the preceding extractions (Fig. 2) and were not different among the groups (Table 2).

The expression of FPN-1, the transporter responsible for cellular Fe efflux, was increased in the caecal mucosa of the FP group ( $P=0.04$; Fig. 3), which accounted for the highest expected absorption efficiency in rats from the FP group

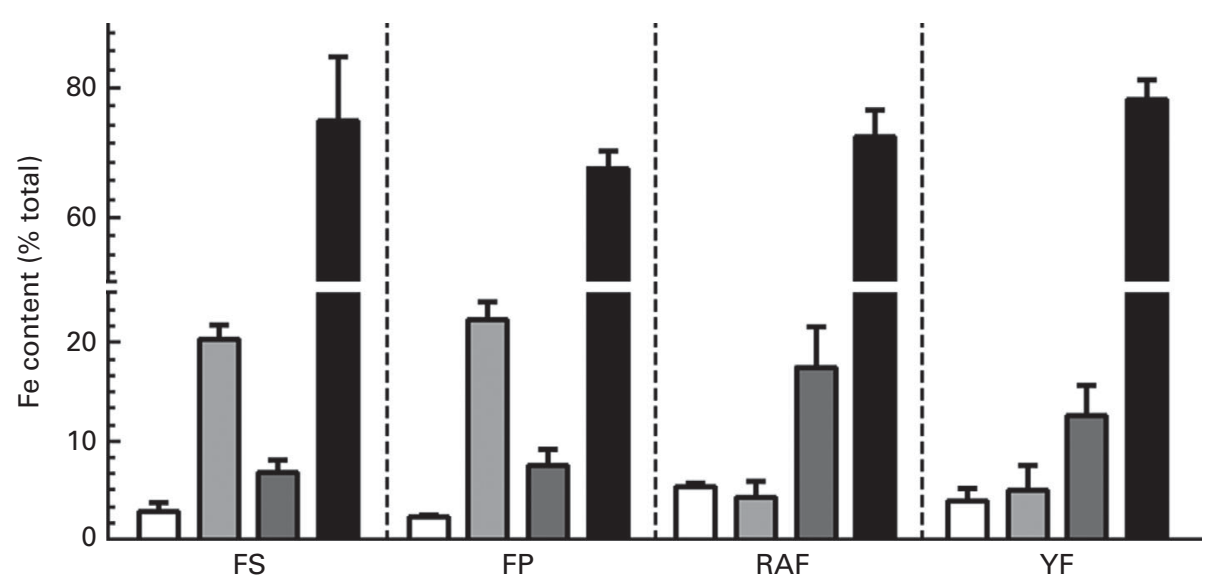

Fig. 2. Effects of fructo-oligosaccharides on the distribution of iron species in caecal contents during the 1st week of recovery of $\mathrm{Hb}$ in anaemic rats. Iron species distribution in the caecal contents of iron-deficient rats fed diets containing ferrous sulphate (FS), ferric pyrophosphate (FP) or FP supplemented with $7.5 \%$ inulintype fructans in the form of Raftilose P95 (RAF) or yacon flour (YF). The fractions are as follows: exchangeable ( $\square$ ); carbonate-bound ( $\square$ ); oxide-bound ( $\square$ ); residual $(\square)$. Values are means $(n 8)$, with standard deviations represented by vertical bars. 

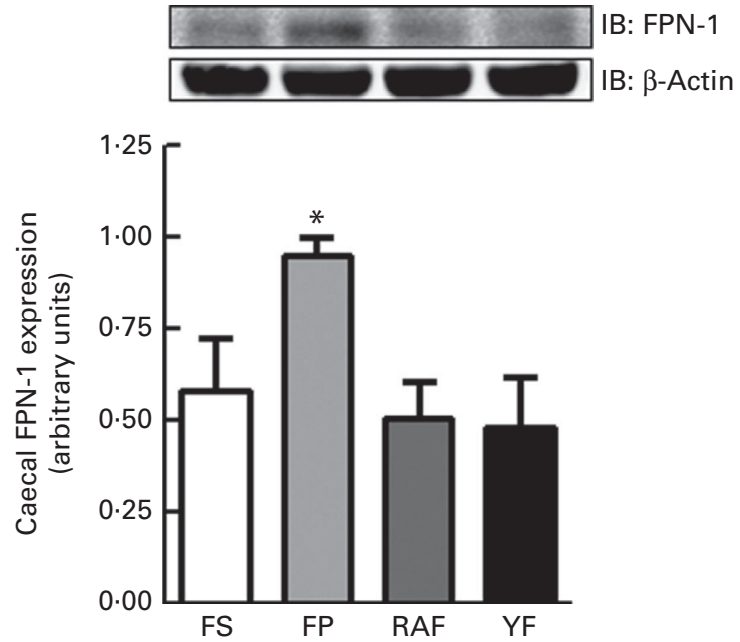

Fig. 3. Effects of fructo-oligosaccharides on ferroportin-1 (FPN-1) expression in the caecal mucosa of anaemic rats during the 1st week of recovery of $\mathrm{Hb}$. FPN-1 expression in the caecal mucosa of iron-deficient rats fed diets containing ferrous sulphate (FS, $\square$ ), ferric pyrophosphate (FP, $\square$ ) or FP supplemented with $7.5 \%$ inulin-type fructans in the form of Raftilose P95 (RAF, $\square$ ) or yacon flour (YF, $\square$ ). Values are means $(n 4)$, with standard deviations represented by vertical bars. *Mean value was significantly different from that of the YF group $(P<0.05$; non-parametric Kruskal-Wallis and Dunn's post hoc tests). IB, immunoblotting.

that still remained anaemic at week 1 of the repletion period. Moreover, there were no differences in FPN-1 expression between FOS-fed rats and FS rats (Fig. 3).

Caecal enlargement was in agreement with the histological changes observed in FOS-fed rats; there was a noticeable increase $(P<0.05)$ in the number of cells per crypt (Fig. 4(A)), the number of crypts per field (Fig. 4(B)) and the percentage of bifurcating crypts per field (Fig. 4(C)) when compared with those in the CT rats. Consistent with these findings, cell proliferation as assessed by the $2 \mathrm{~h}$ accumulation of vincristine-arrested metaphases per crypt was increased by FOS supplementation $(P<0.05)$, and this effect was more pronounced in the RAF group (Fig. 4(D)).

\section{Discussion}

The primary strategies for correcting Fe deficiency in populations are dietary modification or diversification to improve $\mathrm{Fe}$ intake and bioavailability; Fe supplementation and $\mathrm{Fe}$ fortification of foods; and biofortification by plant breeding ${ }^{(31)}$. Although the efficiency of $\mathrm{Fe}$ absorption increases as Fe stores become depleted, the amount absorbed from foods, especially when diets are low in meat, fish, fruit and vegetables, is not enough to prevent Fe deficiency in many women and children, especially in developing countries $^{(31,32)}$. For instance, the primary cause of increasing Fe deficiency in Brazil is that the consumption of food items considered to be Fe sources has continually decreased ${ }^{(33)}$. Indeed, the search for new food standards, proposals for food distribution and knowledge about the dietary composition must be the researcher's target.

The effects of dietary fibre or fibre-rich diets on mineral absorption have been discussed for many years and appear to fundamentally depend on whether they are observed in in vitro or in vivo studies ${ }^{(34,35)}$. On the one hand, some fibres (e.g. cellulose, hemicelluloses and pectin) or fibreassociated substances (e.g. phytates and phenolics) negatively affect the absorption of minerals by binding to or entrapping them in the lumen of the small intestine ${ }^{(35)}$. On the other hand, these negative effects seem to be reduced if the fibres are fermented in the large intestine. In this context, the positive effects of a group of fermentable fibres (namely ITF (FOS and inulin)) on the intestinal absorption and bioavailability of some minerals have been repeatedly demonstrated in $\operatorname{animal}^{(7,12-18)}$ and human ${ }^{(36,37)}$ studies. Most of these studies focused on the bioavailability of $\mathrm{Ca}$ and $\mathrm{Mg}$. Nevertheless, the number of studies concerning the bioavailability of trace elements ( $\mathrm{Fe}, \mathrm{Cu}$ and $\mathrm{Zn}$ ) is proportionally lower, and these studies have thus far yielded contradictory results. In particular, there is some evidence in rats $^{(18,38,39)}$ and pigs $^{(13,14,40,41)}$ that $\mathrm{Fe}$ bioavailability is positively affected. However, these effects have not been consistently demonstrated in human studies ${ }^{(42)}$. To our knowledge, there are no studies that have compared the effects of purified and nonpurified sources of ITF on Fe bioavailability and on histological changes in the large intestine of rats subjected to an experimental model of Fe-deficiency anaemia. We had previously demonstrated the improved bioavailability of $\mathrm{Fe}$ from FP (as measured by $\mathrm{Hb}$ repletion efficiency) by supplementing diets with $7.5 \%$ ITF from either RAF (a purified source)
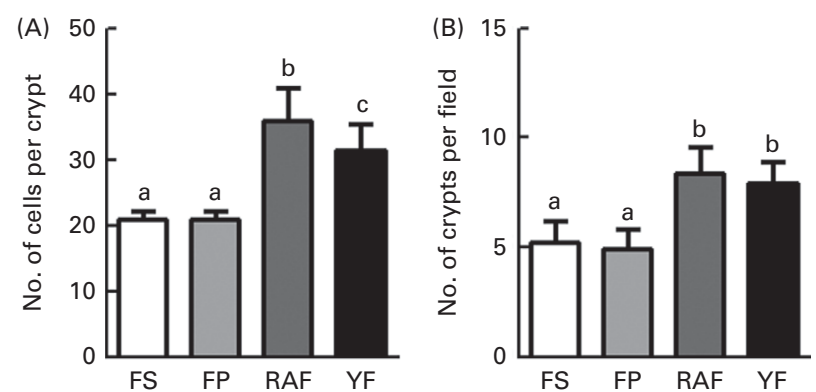

(C)

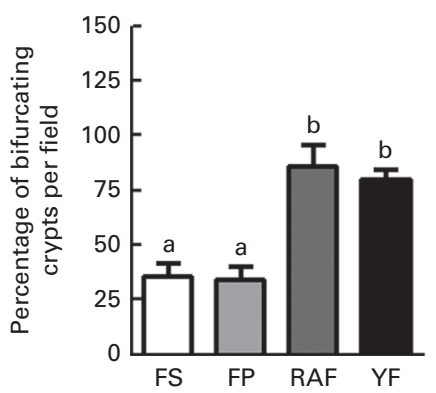

(D)

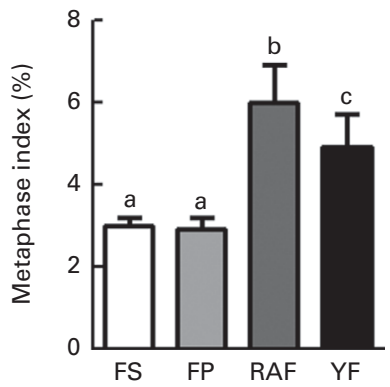

Fig. 4. Changes in the caecal mucosa architecture of iron-deficient rats fed fructo-oligosaccharides during the 1st week of recovery of $\mathrm{Hb}$. The number of cells $(A)$, number of crypts $(B)$, percentage of bifurcating crypts $(C)$ and metaphase index in the crypts (D) in the caecum of iron-deficient rats fed diets containing ferrous sulphate (FS, $\square$ ), ferric pyrophosphate (FP, $\square$ ) or FP supplemented with $7.5 \%$ inulin-type fructans in the form of Raftilose P95 (RAF, $\square$ ) or yacon flour (YF, $\square$ ). Values are means $(n 5)$, with standard deviations represented by vertical bars. ${ }^{\mathrm{a}, \mathrm{b}, \mathrm{c}}$ Mean values with unlike letters were significantly different $(P<0.05$; non-parametric Kruskal-Wallis and Dunn's post hoc tests). 
or yacon tuberous roots (a non-purified source) in anaemic rats ${ }^{(18)}$. In the present study, we confirmed these findings and demonstrated that early changes in the caecal environment (luminal Fe species redistribution, decreased mucosal FPN-1 expression, and morphological alterations) could be related to $\mathrm{Fe}$ bioavailability improvement by FOS supplementation.

Fe in foods is released into the lumen as haem or as nonhaem ferric complexes ${ }^{(43,44)}$. However, non-haem $\mathrm{Fe}$ is most affected by the food matrix composition and the physicochemical conditions in the intestinal lumen ${ }^{(44)}$. Among the various oxidation states of $\mathrm{Fe}$, divalent $\mathrm{Fe}\left(\mathrm{Fe}^{2+}\right)$ and trivalent $\mathrm{Fe}\left(\mathrm{Fe}^{3+}\right)$ are more stable in aqueous media, and they occur naturally in foods ${ }^{(44)}$. The two forms are soluble at the $\mathrm{pH}$ of the stomach; nonetheless, $\mathrm{Fe}^{3+}$ precipitates more rapidly than $\mathrm{Fe}^{2+}$ because of the alkalinisation of the alimentary bolus in the duodenum during the digestive process. However, Fe precipitation can be inhibited by complexing agents in foods, and these agents include amino acids, carboxylic acids, carbohydrates and phosphates ${ }^{(43,44)}$. Thus, factors that affect the luminal $\mathrm{pH}$ or chelating properties of certain dietary components can also affect their redox potential and interfere with their solubility ${ }^{(43,44)}$. In this context, physico-chemical changes in the caecal environment resulting from the bacterial fermentation of non-digestible carbohydrates could contribute to alterations in mineral speciation and thus mineral absorbability $^{(10,11,18,45)}$. In the present study, the lower luminal $\mathrm{pH}$ observed in the caecum of FOS-fed rats could have contributed to Fe mobilisation from the carbonate-bound to the exchangeable and oxide-bound fractions. Only $10 \%$ of dietary $\mathrm{Fe}$ is absorbed in the small intestine (primarily in the duodenum), which indicates that significant amounts of $\mathrm{Fe}$ are recovered in the luminal content of the large intestine ${ }^{(46)}$. Thus, our findings indicate that FOS fermentation could have increased the fraction of $\mathrm{Fe}$ available for uptake in the caecum by approximately $15 \%$.

Complementarily, mucosal FPN-1 expression in the caecum was decreased in FOS-fed rats at a magnitude similar to that in the FS group. Some studies have also demonstrated that, under specific circumstances, the proximal colon may significantly contribute to Fe absorption ${ }^{(13,40,47,48)}$. In fact, feeding rats with an Fe-deficient diet induces an increase in the gene expression of Fe transporters (DCYTB, FPN-1 and DMT-1) both in the duodenum and in the large intestine ${ }^{(48)}$. Accordingly, the highest caecal FPN-1 expression in FP animals is consistent with the fact that these animals were still anaemic after 1 week of repletion. Some authors have suggested that the expansion of the caecal compartment by fibre fermentation could contribute to Fe absorption via enhanced DMT-1 expression $^{(49)}$. Caecal enlargement has been observed frequently and tends to be proportional to the fermentability of dietary fibre ${ }^{(7,18,22,50)}$. In this context, this trophic effect was believed to be caused by the SCFA (particularly butyrate) that are produced as a result of the increased metabolic activity of the microbiota ${ }^{(1,8,50-52)}$. Butyrate is recognised as the primary source of energy for colonocytes, playing an important role in the stimulus of cell division in the intestinal mucosa ${ }^{(51,52)}$. We had previously demonstrated increased caecal SCFA production by FOS supplementation and found $\mathrm{YF}$ to be more butyrogenic than $\mathrm{RAF}^{(18)}$. However, the yacon roots used in that study had lower fructan contents than those used in the present study $\left(18 \%{ }^{(18)} v\right.$. 48\%), most probably because of the increased fructan depolymerisation catalysed by fructan 1-exohydrolase ${ }^{(53)}$, which led us to use a larger amount of $\mathrm{YF}$ in the formulation of experimental diets $\left(41 \cdot 7 \%{ }^{(18)} v \cdot 15 \cdot 7 \%\right)$. Thus, although the fructan content was the same $(7.5 \%)$ in the different diets (RAF and YF), the dietary fibre (soluble and insoluble) concentrations (as measured by the enzymatic-gravimetric method ${ }^{(24)}$ ) in the additional YF used for diet formulation may have contributed to the higher fermentability observed in the YF group in that study ${ }^{(18)}$. In fact, in the present study, besides exhibiting a lower caecal content $\mathrm{pH}$, RAF rats also had heavier caeca compared with YF rats. Factors other than dietary fibre fermentability may also directly influence the mucosal growth of the caecum, such as increased intestinal content viscosity ${ }^{(2)}$. In addition, caecum weight can be influenced by stool water content because FOS remain in solution in the chyme and contribute to increased osmotic pressure, resulting in increased water flow to the intestinal lumen ${ }^{(16,17,54)}$

Bacterial fermentation has also been implicated in morphological changes in the intestinal epithelium of FOS-fed animals. In this context, germ-free rats were found to exhibit an increase in intestinal weights, but exhibited no proliferative effects in the intestinal mucosa in response to fibre consumption, confirming that the fermentation products (SCFA) are responsible for trophic effects on the intestinal mucosa ${ }^{(3,55)}$ Thus, that FOS-containing diets indirectly affect mucosal morphometry (with increases in the number and depth of crypts and crypt bifurcation) in the rat large intestine has previously been demonstrated by us ${ }^{(7,15)}$ and other authors ${ }^{(3,55)}$. Moreover, the increased number of caecal crypts was supported by the present data on crypt cell proliferation and bifurcation, which are complementary mechanisms to increase tissue mass and were stimulated upon FOS supplementation. The production of new crypts by fission is a process that is thought to be related to the expansion of the crypt stem cell population and is increased in postnatal development, during intestinal recovery from injury and in crypts isolated from adenomas and hyperplastic polyps ${ }^{(30,56,57)}$. Thus, FOS fermentability must be addressed with some caution, because the observed effects may, on the one hand, be interesting for promoting mineral absorption and bioavailability by increasing the absorptive surface and contributing to the improvement of mineral solubility in the caecum. On the other hand, the intestinal changes caused by this type of carbohydrate (rapidly fermentable) have been linked to the promotion of intestinal tumour development ${ }^{(57,58)}$. Furthermore, some studies in rats have demonstrated detrimental effects on the intestinal barrier function after FOS supplementation in Ca-restricted diets ${ }^{(5,59)}$. Thus, from a nutritionist's point of view, a dietary prescription for fermentable fibres should consider not only the type and amount of fibre but also whether the consumed fibre is given in a purified or nonpurified form. In addition, the composition of the food 
matrix, in which the fibre is present, is another important factor to be taken into consideration.

In conclusion, dietary FOS supplementation improves $\mathrm{Fe}$ bioavailability in anaemic rats by changing luminal Fe solubility, most probably as a result of bacterial fermentation in the caecum. These effects were more pronounced on using a purified source (RAF) than on using a non-purified source (YF) of fructans. These effects, if confirmed in humans, might contribute to the formulation of specific diets for individuals with Fe deficiency. The changes observed in the caecal tissue of FOS-fed animals must be evaluated with caution because increased cell proliferation and crypt fission have been implicated in the carcinogenic process within the large intestine.

\section{Acknowledgements}

The authors thank Cruz Alberto Mendoza Rigonatti and Natália Nadur de Souza for their technical assistance, the Fundação de Amparo à Pesquisa do Estado de São Paulo (2009/01760-8) for supporting this research and the Conselho Nacional de Desenvolvimento Científico e Tecnológico for the fellowships awarded to A. R. L. (505758/2008-3) and C. C. (309026/2009-1). The present study was also supported by the Coordenação de Aperfeiçoamento de Pessoal de Nível Superior.

The authors' contributions are as follows: A. R. L. was responsible for the study concept and design and for the acquisition, analysis and interpretation of the data; E. H. S. G. and E. D. C. were responsible for the acquisition and analysis of the data; E. P. A. was responsible for the acquisition, analysis and interpretation of the data; C. C. was responsible for the study concept and design, acquired, analysed and interpreted the data, and obtained funding.

The authors declare no financial, professional or personal conflicts of interest.

\section{References}

1. Gibson GR \& Roberfroid MB (2005) Dietary modulation of the human colonic microbiota: introducing the concept of prebiotics. J Nutr 125, 1401-1412.

2. Hara H, Suzuki K, Kobayashi S, et al. (1996) Fermentable property of dietary fiber may not determine cecal and colonic mucosal growth in fiber-fed rats. J Nutr Biochem 7 , $549-554$

3. Kleessen B, Hartmann L \& Blaut M (2003) Fructans in the diet cause alterations of intestinal mucosal architecture, released mucins and mucosa-associated bifidobacteria in gnotobiotic rats. Br J Nutr 89, 597-606.

4. Goodlad RA, Lenton W, Ghatei MA, et al. (1987) Effects of an elemental diet, inert bulk and different types of dietary fiber on the response of the intestinal epithelium to refeeding in the rat and relationship to plasma gastrin, enteroglucagon, and PYY concentrations. Gut 28, 171-180.

5. Ten Bruggencate SJM, Bovee-Oudenhoven IMJ, LettinkWissink MLG, et al. (2005) Dietary fructooligosaccharides increase intestinal permeability in rats. J Nutr 135, 837-842.

6. Ishizuka S, Tanaka S, Xu H, et al. (2004) Fermentable dietary fiber potentiates the localization of immune cells in the rat large intestinal crypts. Exp Biol Med 229, 876-884.
7. Lobo AR, Mancini Filho J, Alvares EP, et al. (2009) Effect of dietary lipid and inulin-type fructans on mineral bioavailability in rats. Nutrition 25, 216-225.

8. Walker AW, Duncan SH, Leitch ECM, et al. (2005) pH and peptide supply can radically alter bacterial populations and short-chain fatty acid ratios within microbial communities from the human colon. Appl Environ Microbiol 71, 3692-3700.

9. Moran-Ramos S, Tovar AR \& Torres N (2012) Diet: friend or foe of enteroendocrine cells: how it interacts with enteroendocrine cells. Adv Nutr 3, 8-20.

10. Levrat MA, Rémésy C \& Demigné C (1991) High propionic acid fermentations and mineral accumulation in the cecum of rats adapted to different levels of inulin. J Nutr 121, $1730-1737$.

11. Rémésy C, Levrat MA, Gamet L, et al. (1993) Cecal fermentations in rats fed oligosaccharides (inulin) are modulated by dietary calcium level. Am J Physiol 264, G855-G862.

12. Nzeusseu A, Dienst D, Haufroid V, et al. (2006) Inulin and fructo-oligosaccharides differ in their ability to enhance the density of cancellous and cortical bone in the axial and peripheral skeleton in growing rats. Bone 37, 394-399.

13. Tako E, Glahn RP, Welch RM, et al. (2008) Dietary inulin affects the expression of intestinal enterocyte iron transporters, receptors and storage protein and alters the microbiota in the pig intestine. Br J Nutr 99, 472-480.

14. Tako E, Yasuda K, Glahn RP, et al. (2006) Dietary inulin upregulates the expression of iron and zinc membrane transporters in intestinal enterocytes in the pig. FASEB J 20, LB97.

15. Lobo AR, Colli C, Alvares EP, et al. (2007) Effects of fructanscontaining yacon (Smallanthus sonchifolius Poepp \& Endl.) flour on caecum mucosal morphometry, calcium and magnesium balance and bone calcium retention in growing rats. Br J Nutr 97, 766-785.

16. Lobo AR, Colli C \& Filisetti TMCC (2006) Fructooligosaccharides improve bone mass and biomechanical properties in rats. Nutr Res 26, 413-420.

17. Lobo AR, Cocato ML, Jorgetti V, et al. (2009) Changes in bone mass, biomechanical properties, and microarchitecture of calcium- and iron-deficient rats fed diets supplemented with inulin-type fructans. Nutr Res 29, 873-881.

18. Lobo AR, Cocato ML, Borelli P, et al. (2011) Iron bioavailability from ferric pyrophosphate in rats fed with fructancontaining yacon (Smallanthus sonchifolius) flour. Food Chem 126, 885-891.

19. Association of Official Analytical Chemists (2006) Official Methods of Analysis of Association of Official Analytical Chemists, chapter 45, 18th ed., pp. 80-81. Gaithersburg, MD: AOAC International (Current through Revision 1).

20. Reeves PG, Nielsen FH \& Fahey GC Jr (1993) AIN-93 purified diets for laboratory rodents: final report of the American Institute of Nutrition ad hoc writing committee on reformulation of the AIN-76A rodent diet. J Nutr 123, 1939-1951.

21. Cocato ML, Ré MI, Trindade Neto MA, et al. (2007) Avaliação por métodos in vitro e in vivo da biodisponibilidade de sulfato ferroso microencapsulado (In vitro and in vivo evaluation of iron bioavailability from microencapsulated ferrous sulfate). Braz J Nutr 20, 239-247.

22. Lu ZX, Gibson PR, Muir JG, et al. (2000) Arabinoxylan fiber from a by-product of wheat flour processing behaves physiologically like a soluble, fermentable fiber in the large bowel of rats. J Nutr 130, 1984-1990.

23. Steegmans M, Iliaens S \& Hoebregs H (2004) Enzymatic, spectrophotometric determination of glucose, fructose, sucrose, and inulin/oligofructose in foods. J AOAC Int $\mathbf{8 7}$, 1200-1207. 
24. Prosky L, Asp NG, Schweizer TF, et al. (1988) Determination of insoluble, soluble, and total dietary fiber in foods and food products: interlaboratory study. $J A O A C$ Int $\mathbf{7 1}$, $1017-1023$.

25. Drabkin DL \& Austin JH (1935) Spectrophotometric studies II. Preparations from washed blood cells: nitric oxide hemoglobin and sulphemoglobin. $J$ Biol Chem 112, 51-65.

26. Mahoney AW, Van Orden CC \& Hendricks DG (1974) Efficiency of converting food iron into haemoglobin by the anaemic rat. Nutr Metabol 17, 223-230.

27. Poltronieri F, Arêas JAG \& Colli C (2000) Effect of iron bioavailability in chickpea (Cicer arietinum L.). Food Chem 70, 175-180

28. Simpson RJ, Sidhar S \& Peters TJ (1992) Application of selective extraction to the study of iron species present in diet and rat gastrointestinal tract contents. Br J Nutr 67, 437-444.

29. Tessier A, Campbell PGC \& Bisson M (1979) Sequential extraction procedure for the speciation of particulate trace metals. Anal Chem 51, 844-851.

30. Maskens AP (1978) Histogenesis of colon glands during postnatal growth. Acta Anat 100, 17-26.

31. Zimmermman MB \& Hurrel RF (2007) Nutritional iron deficiency. Lancet 370, 511-520.

32. Benito P, House W \& Miller D (1997) Influence of iron supplementation frequency on absorption efficiency and mucosal ferritin in anaemic rats. Br J Nutr 78, 469-477.

33. Szarfarc SC (2006) Histórico das políticas públicas para o controle da deficiência de ferro no Brasil. In $O$ ferro $e$ a saúde das populações, 1st ed., pp. 200-212 [JAP Braga, OMS Amancio and MSS Vitalle, editors]. São Paulo: Roca.

34. Kelsay JL, Behall KM \& Prather ES (1979) Effect of fiber from fruits and vegetables on metabolic responses of human subjects. II. Calcium, magnesium, iron and silicon balances. Am J Clin Nutr 32, 1876-1880.

35. Fernandez R \& Phillips SF (1982) Components of fiber bind iron in vitro. Am J Clin Nutr 35, 100-106.

36. Van Der Heuvel EGHM, Muys T, Van Dokkum W, et al. (1999) Oligofructose stimulates calcium absorption in adolescents. Am J Clin Nutr 69, 544-548.

37. Abrams SA, Griffin IJ \& Hawthorne KM (2007) Young adolescents who respond to an inulin-type fructan substantially increase total absorbed calcium and daily calcium accretion to the skeleton. J Nutr 137, 2524S-2526S.

38. Weber TK, Freitas KC, Amancio OMS, et al. (2010) Effect of dietary fibre mixture on growth and intestinal iron absorption in rats recovering from iron-deficiency anaemia. $\mathrm{Br} \mathrm{J}$ Nutr 104, 1471-1476.

39. Freitas KC, Amancio OMS \& Morais MB (2012) Highperformance inulin and oligofructose prebiotics increase the intestinal absorption of iron in rats with iron deficiency anaemia during the growth phase. $B r J$ Nutr $\mathbf{1 0 8}$, $1008-1016$

40. Yasuda K, Urban JF, Dawson HD, et al. (2009) Supplemental dietary inulin influences expression of iron and inflammation related genes in young pigs. J Nutr 139, 2018-2023.

41. Patterson JK, Yasuda K, Welch RM, et al. (2010) Supplemental dietary inulin of variable chain lengths alters intestinal bacterial populations in young pigs. J Nutr 140, 2158-2161.

42. Petry N, Egli I, Chassard C, et al. (2012) Inulin modifies the bifidobacteria population, fecal lactate concentration, and fecal $\mathrm{pH}$ but does not influence iron absorption in women with low iron status. Am J Clin Nutr 96, 325-331.
43. Cremonesi P, Acebron A, Raja KB, et al. (2002) Iron absorption: biochemical and molecular insights into the importance of iron species for intestinal uptake. Pharmacol Toxicol 91, 97-102.

44. Colli C (2006) Biodisponibilidade de ferro. In $O$ ferro e a saúde das populações, 1st ed., pp. 45-65 [JAP Braga, OMS Amancio and MSS Vitalle, editors]. São Paulo: Roca.

45. Yasuda K, Roneker KR, Miller DD, et al. (2006) Supplemental dietary inulin affects the bioavailability of iron in corn and soybean meal to young pigs. J Nutr 136, 3033-3038.

46. Lund EK, Wharf SG, Fairweather-Tait SJ, et al. (1998) Increases in the concentrations of available iron in response to dietary iron supplementation are associated with changes in crypt cell proliferation in rat large intestine. J Nutr 128, 175-179.

47. Frazer DM, Wilkins SJ \& Anderson GJ (2007) Elevated iron absorption in the neonatal rat reflects high expression of iron transport genes in the distal alimentary tract. $A m J$ Physiol 293, G525-G531.

48. Takeuchi K, Bjarnason I, Laftah AH, et al. (2005) Expression of iron absorption genes in mouse large intestine. Scand J Gastroenterol 40, 169-177.

49. Hara H, Onoshima S \& Nakagawa C (2010) Difructose anhydride promotes iron absorption in the rat large intestine. Nutrition 26, 120-127.

50. Campbell JM, Fahey GC Jr \& Wolf B (1997) Selected indigestible oligosaccharides affect large bowel mass, cecal and fecal short-chain fatty acids, $\mathrm{pH}$ and microflora in rats. J Nutr 127, 130-136.

51. Sakata T (1987) Stimulatory effect of short-chain fatty acids on epithelial cell proliferation in the rat intestine: a possible explanation for trophic effects of fermentable fibre, gut microbes and luminal trophic factors. Br J Nutr 58, 95-103.

52. Weaver GA, Tangel CT, Krause JA, et al. (2000) Biomarkers of human colonic cell growth are influenced differently by a history of colonic neoplasia and the consumption of acarbose. J Nutr 130, 2718-2725.

53. Itaya NM, Carvalho MAM \& Figueiredo-Figueiredo RCL (2002) Fructosyl transferase and hydrolase activities in rizophores and tuberous roots upon growth of Polymnia sonchifolia (Asteraceae). Physiol Plant 116, 451-459.

54. Leegwater DC, De Groot AP \& Van Kalmthout-Kuyper M (1974) The aetiology of caecal enlargement in the rat. Food Cosmet Toxicol 12, 687-697.

55. McCullough JS, Ratcliffe B, Mandir N, et al. (1998) Dietary fibre and intestinal microflora: effects on intestinal morphometry and crypt branching. Gut 42, 799-806.

56. Cheng L, Araki K, Furuya Y, et al. (2000) Morphological study of the regeneration mechanism of acetic acid-injured colon crypts in the rat. Med Electron Microsc 33, 165-171.

57. Goodlad RA \& Englyst HN (2001) Redefining dietary fibre: potentially a recipe to disaster. Lancet 358, 1833-1834.

58. Mandir N, Englyst H \& Goodlad RA (2008) Resistant carbohydrates stimulate cell proliferation and crypt fission in wild-type mice and in the $A P C^{\mathrm{Min} /+}$ mouse model of intestinal cancer, associated with enhanced polyp development. Br J Nutr 100, 711-721.

59. Ten Bruggencate SJ, Bovee-Oudenhoven IM, Lettink-Wissink ML, et al. (2004) Dietary fructo-oligosaccharides and inulin decrease resistance of rats to Salmonella: protective role of calcium. Gut 53, 530-535. 